Rodrigo de Campos Costa, Delegado de Polícia Federal, especialista, mestre e doutorando em Direito Processual Penal pela PUC-SP

Área do Direito: Direito Penal

Resumo: O presente artigo tem por finalidade discutir e analisar a Lei 12.850/13, especialmente, no que se refere ao conceito de grupo criminoso organizado e sua tipificação, fazendo uma breve abordagem histórica a respeito da Lei 9034/95 e da Convenção de Palermo. Também apontamos algumas características, típicas de grupos criminosos organizados.

Palavras-Chave: Crime organizado; grupo criminoso organizado; Convenção de Palermo; tipificação de organização criminosa.

Sumário:1. Conceito, legislação e característica;

Abstract: This article aims to discuss and analyze the Law 12.850/13, especially in relation to organized criminal group concept and its classification, making a brief historical approach about the Law 9034/95 and the Palermo Convention. Also we point out some characteristics typical of organized criminal groups.

Keywords: Organized crime; organized criminal group; Palermo Convention; typifying criminal organization.

\title{
CRIMINALIDADE ORGANIZADA;
}

1.Conceito, legislação e características; 2. CONCLUSÃO.

Façamos, antes da análise, um breve resgate histórico a respeito da legislação brasileira que tratava o tema "criminalidade organizada".

A primeira legislação que fez menção à criminalidade organizada era a Lei 9034/95. Referida lei era de duvidosa constitucionalidade, bem como possuía redação de difícil compreensão.

Malgrado o instituto legal fizesse menção à criminalidade organizada, na verdade, os instrumentos nela previstos estavam relacionados ao cometimento de crimes de quadrilha ou bando, ou seja, no tipo penal previsto no Art.288 do Código Penal Brasileiro, razão pela qual seus institutos eram aplicados indiscriminadamente nestes casos.

Os instrumentos inovadores trazidos pela Lei 9034/95 foram, resumidamente, a ação controlada, a infiltração policial, delação premiada e a possibilidade de captação de áudio ambiental. 
Referidas técnicas de obtenção de prova, ou de obtenção do dado negado, fazem parte das Técnicas Especiais de Investigação, previstas inicialmente no art.20 da Convenção de Palermo $^{1}$ e que serão oportunamente melhor descritas, cuja redação segue in verbis:

1. Se os princípios fundamentais do seu ordenamento jurídico nacional o permitirem, cada Estado-Parte, tendo em conta as suas possibilidades e em conformidade com as condições prescritas no seu direito interno, adotará as medidas necessárias para permitir o recurso apropriado a entregas vigiadas e, quando o considere adequado, o recurso a outras técnicas especiais de investigação, como a vigilância eletrônica ou outras formas de vigilância e as operações de infiltração, por parte das autoridades competentes no seu território, a fim de combater eficazmente a criminalidade organizada.

Mesmo com a previsão explícita de tais institutos, os quais, em tese, poderiam ser utilizados nos crimes de quadrilha ou bando, novamente a Lei 9034/95 padeceu em falha, na medida em que não previu mecanismos para sua utilização, ou seja, ao prever e conceituar a ação controlada, por exemplo, não estabeleceu a forma, vale dizer, o procedimento para materialização do meio de prova, tais como: prazo de duração, controle jurisdicional, necessidade de relatório de investigação e etc.

Maior dificuldade ainda era a utilização da infiltração policial, pois ausente estava qualquer forma de regulamentação a respeito deste meio tão especial de obtenção de prova.

A ausência de definição legal de criminalidade organizada e de seus procedimentos, naquele momento histórico, seguramente causou enormes prejuízos e trouxe insegurança jurídica neste tipo especial de enfrentamento.

E quando fala-se em insegurança jurídica, é possível a interpretação sob dois aspectos, quais sejam: o primeiro, por deixar a sociedade mais insegura, ante a impossibilidade de utilização dos meios de prova nela dispostos; o segundo, pela utilização desproporcional destes mecanismos em delitos de menor importância.

Diante deste contexto, os operadores do direito, a jurisprudência e a doutrina, procuraram fornecer elementos e subsídios que dessem supedâneo à aplicação da lei, pois a sociedade não poderia arcar com ônus da insegurança diante da inépcia legislativa.

${ }^{1}$ Disponível em: <http://www.planalto.gov.br/ccivil_03/_ato2004-2006/2004/decreto/d5015.htm>, acesso em $07 / 09 / 2016$ 
A ausência de definição de organização criminosa, no entendimento de ANTONIO SCARANCE FERNANDES ${ }^{2}$ " [...] impossibilita a restrição a direitos e garantias do investigado, do acusado, do condenado, com fundamento no fato de pertencer a esse tipo de entidade [...]".

Com relação aos operadores do direito, não podemos deixar de mencionar a atuação da Polícia Federal em investigações envolvendo a criminalidade organizada, onde procurou, respeitando o Estado Democrático de Direito e a Constituição Federal, especialmente, no seu art. $5^{\circ}$, no que diz respeito aos direitos e garantias individuais, colaborar com inovações na utilização destes instrumentos.

A ação controlada, por exemplo, teve sua utilização aferida em diversas operações especiais, das quais fizemos parte, sempre precedida de autorização judicial, mesmo diante do vácuo legislativo - no qual não fazia menção a essa necessidade - ; a captação ambiental de áudio, de igual sorte precedida de autorização judicial e com aplicação analógica da Lei 9296/96, quando houvesse a necessidade de continuidade da medida excepcional.

Procurando preencher o vácuo legislativo foi promulgada a Lei 10.271/01, a qual acrescentou a possibilidade de utilização da lei às "organizações e associações criminosas". Mas ainda assim, pairava a dúvida, o que seriam "organizações criminosas", pois a associação criminosa encontrava definição na Lei de Drogas no seu $\operatorname{art} .35$.

Obviamente que a necessidade de se estabelecer o conceito de criminalidade organizada chegou aos nossos tribunais superiores, oportunidade em que o Superior Tribunal de Justiça ${ }^{3}$, através do voto da Ministra Laurita Vaz manifestou-se no seguinte sentido:

\section{$[\ldots]$}

2. Capitulação da conduta no inciso VII do art. 1. ${ }^{\circ}$ da Lei n. ${ }^{\circ}$ 9.613/98, que não requer nenhum crime antecedente específico para efeito da configuração do crime de lavagem de dinheiro, bastando que seja praticado por organização criminosa, sendo esta disciplinada no art. $1 .^{\circ}$ da Lei n. $^{\circ}$ 9.034/95, com a redação dada pela Lei n. ${ }^{\circ} 10.217 / 2001$, c.c. o Decreto Legislativo n. ${ }^{\circ} 231$, de 29 de maio de 2003 , que ratificou a Convenção das

\footnotetext{
${ }^{2}$ O Equilíbrio na Repressão ao Crime Organizado, p.15.

${ }^{3}$ BRASIL, Superior Tribunal de Justiça, Penal, HC 77771, $5^{\text {a }}$ Turma, Relatora Ministra Laurita Vaz, DJ 30/05/2008;
} 
Nações Unidas contra o Crime Organizado Transnacional, promulgada pelo Decreto n. ${ }^{\circ}$ 5.015, de 12de março de 2004. Precedente.

$[\ldots]$

Ou seja, adotou-se o conceito estabelecido pela Convenção de Palermo ${ }^{4}$, da qual o Brasil outrora fora signatário, o qual assim dispõe, in verbis:

\author{
Artigo 2 \\ Terminologia \\ Para efeitos da presente Convenção, entende-se por:
}

a) "Grupo criminoso organizado" - grupo estruturado de três ou mais pessoas, existente há algum tempo e atuando concertadamente com o propósito de cometer uma ou mais infrações graves ou enunciadas na presente Convenção, com a intenção de obter, direta ou indiretamente, um benefício econômico ou outro benefício material;

Destaque-se que a doutrina, especialmente, a produzida pela Polícia Federal já vinha se manifestando nesse sentido, conforme leciona LUIZ ROBERTO UNGARETTI DE GODOY 5 :

Conforme narrado no início do Capítulo, demonstramos que o ordenamento jurídico brasileiro não definiu crime organizado na Lei $n^{\circ}$ 9034/1995, nem tampouco na Lei $\mathrm{n}^{\mathrm{o}} 10.271 / 2001$.

Contudo, com a promulgação da Convenção das Nações Unidas contra o Crime Organizado Transnacional, conhecida como "Convenção de Palermo, recepcionada pelo Decreto $\mathrm{n}^{\circ} 5015$, de 12 de março de 2004, finalmente surgiu no ordenamento jurídico brasileiro, com força de lei ordinária, um conceito sobre grupo criminoso organizado [...].

Também no âmbito da Polícia Federal, RODRIGO CARNEIRO GOMES ${ }^{6}$, um dos primeiros a se manifestar sobre o tema, assim lecionou:

Não há tipificação legal, embora o Brasil, como signatário da Convenção de Palermo (Decreto 5.015, de 12/03/2004), tenha se comprometido a tipificar as organizações ilícitas que objetivam lucro como modalidade criminosa.

\footnotetext{
${ }^{4}$ Disponível em: <http://www.planalto.gov.br/ccivil_03/_ato2004-2006/2004/decreto/d5015.htm> acesso em 07/09/2016;

${ }^{5}$ Crime Organizado e seu Tratamento Jurídico Penal, p.73-74;

${ }^{6}$ O Crime Organizado na Visão da Convenção de Palermo, p.19;
} 
Passados mais de uma década, o Congresso Nacional aprovou a Lei 12.850/2011 ${ }^{7}$, cuja redação em seu artigo inicial assim dispôs, in verbis:

Art. 1ำ Esta Lei define organização criminosa e dispõe sobre a investigação criminal, os meios de obtenção da prova, infrações penais correlatas e o procedimento criminal a ser aplicado.

Nesse mesmo ano, houve também a edição da Lei 12.694/2011, cuja finalidade consiste na proteção de magistrados que tinham sua atuação voltada a investigações de criminalidade organizada, na medida em que previa a possibilidade de atuação mediante colegiado $^{8}$ em decisões no bojo de ações criminais voltadas ao crime organizado.

Referida leia prevê em seu art. $1^{\text {o9 }}$, in verbis:

Art. 1ํ Em processos ou procedimentos que tenham por objeto crimes praticados por organizações criminosas, o juiz poderá decidir pela formação de colegiado para a prática de qualquer ato processual, especialmente:

I - decretação de prisão ou de medidas assecuratórias;

II - concessão de liberdade provisória ou revogação de prisão;

III - sentença;

IV - progressão ou regressão de regime de cumprimento de pena;

V - concessão de liberdade condicional;

VI - transferência de preso para estabelecimento prisional de segurança máxima; e

VII - inclusão do preso no regime disciplinar diferenciado.

$\S$ 1ํ O juiz poderá instaurar o colegiado, indicando os motivos e as circunstâncias que acarretam risco à sua integridade física em decisão fundamentada, da qual será dado conhecimento ao órgão correicional.

\footnotetext{
7 Disponível em:<http://www.planalto.gov.br/ccivil_03/_ato2011-2014/2013/lei/112850.htm>acesso em 07/09/2016.

${ }^{8}$ A intenção do legislador ao prever a possibilidade de atuação em colegiado por parte dos magistrados, era justamente pulverizar a identidade do juiz, de modo a não identificá-lo pessoalmente na condução do processo.

${ }^{9}$ Disponível em: <http://www.planalto.gov.br/ccivil_03/_ato2011-2014/2012/lei/112694.htm> acesso em $12 / 09 / 2016$
} 
$\S 2^{\mathrm{o}} \mathrm{O}$ colegiado será formado pelo juiz do processo e por 2 (dois) outros juízes escolhidos por sorteio eletrônico dentre aqueles de competência criminal em exercício no primeiro grau de jurisdição.

$\S 3^{\circ}$ A competência do colegiado limita-se ao ato para o qual foi convocado.

$\S 4^{\circ}$ As reuniões poderão ser sigilosas sempre que houver risco de que a publicidade resulte em prejuízo à eficácia da decisão judicial.

$\S 5^{\circ}$ A reunião do colegiado composto por juízes domiciliados em cidades diversas poderá ser feita pela via eletrônica.

$\S 6^{\circ}$ As decisões do colegiado, devidamente fundamentadas e firmadas, sem exceção, por todos os seus integrantes, serão publicadas sem qualquer referência a voto divergente de qualquer membro.

$\S 7$ o Os tribunais, no âmbito de suas competências, expedirão normas regulamentando a composição do colegiado e os procedimentos a serem adotados para o seu funcionamento.

Com relação ao conceito de crime organizado, a redação é absolutamente semelhante à prevista na Lei 12.850/2011.

A novel legislação, a nosso ver, avançou e teve seus méritos, na medida em que convergiu com o compromisso assumido pela adoção da Convenção de Palermo, pois assim o fez: conceituou organização criminosa; assumiu a opção legislativa de tipificar o fato de "integrar" organização criminosa; definiu os meios de prova, estabelecendo, minudentemente, os seus procedimentos; instituiu a possibilidade afastamento cautelar de funcionário público envolvido com organização criminosa, dentre outros.

O $\S 1^{\circ}$ do art. $1^{\circ}$ da Lei $12.850 / 2011^{10}$ assim definiu a organização criminosa, in verbis:

$\S 1^{\text {o }}$ Considera-se organização criminosa a associação de 4 (quatro) ou mais pessoas estruturalmente ordenada e caracterizada pela divisão de tarefas, ainda que informalmente, com objetivo de obter, direta ou indiretamente, vantagem de qualquer natureza, mediante a prática de infrações penais cujas penas máximas sejam superiores a 4 (quatro) anos, ou que sejam de caráter transnacional.

10 Disponível em: <http://www.planalto.gov.br/ccivil_03/_ato2011-2014/2013/lei/112850.htm> acesso em 07/09/2016 
É evidente que, a partir da promulgação da Lei de Organizações Criminosas, os órgãos de persecução passaram a ter mais segurança na utilização dos meios probatórios nela dispostos, haja vista não haver mais a necessidade de socorrer-se da doutrina ou da jurisprudência, a lei é sua fonte imediata de consulta.

A Lei $n^{\circ}$ 12.850/2011 divergiu da Convenção de Palermo no que se refere ao conceito de organização criminosa, na medida em que, para esta o grupo criminoso organizado necessita para sua configuração o mínimo de 3 (três) pessoas, ao passo que para àquela há a necessidade de 4 (quatro) pessoas para sua configuração.

Inovou também a novel lei, na tipificação prevista no art. $2^{\circ 11}$, conforme segue, in verbis:

Art. 2o Promover, constituir, financiar ou integrar, pessoalmente ou por interposta pessoa, organização criminosa:

Pena - reclusão, de 3 (três) a 8 (oito) anos, e multa, sem prejuízo das penas correspondentes às demais infrações penais praticadas.

Analisando o tipo penal dogmaticamente, pode-se dizer que trata-se de crime de perigo abstrato, na medida em que o mero fato de promover, constituir, financiar ou integrar organização criminosa, são elementos suficientes e aptos à configuração do delito previsto na Lei acima destacada, independente da ocorrência de outros crimes a serem praticados pela sobredita organização criminosa.

Por se tratar de hipótese de antecipação de tutela penal, há posicionamento na doutrina reticente em aceitar a legitimidade deste tipo penal, seara vasta no tocante aos crimes de perigo abstrato, onde estaria caracterizado a manifestação do Direito Penal Simbólico, através de legislação de emergência.

Nesse sentido, em ANTÔNIO SÉRGIO ALTIERI DE MORAES PITOMBO ${ }^{12}$ : "No entanto, a ineficácia de tais tipos patenteia-se com o fracasso da denominada antecipação punitiva."

A despeito de posições em sentido contrário à tipificação do crime de organização de criminosa, importante trazer à baila a manifestação de GÜNTHER JAKOBS e MIGUEL POLAINO ORTS ${ }^{13}$ a respeito do tema, oportunidade em que se

\footnotetext{
${ }^{11}$ Ibidem.

12 Organização Criminosa, Nova Perspectiva do Tipo Legal, p.155.

13 Delitos de Organización: Un desafío al Estado, p.144 (tradução livre do autor).
} 
manifestam favoráveis à tipificação autônoma, no entanto, a referida criminalização deve se dar de maneira excepcional, atendendo a critérios de segurança jurídica, conforme segue:

[...] a associação ilícita deve ter, para ser punível, uma força estrutural de tal entidade que seja idônea para abalar as bases do Estado e impedir os cidadãos que possam desenvolver seu projeto pessoal dentro de parâmetros mínimos de segurança.

$[\ldots]$

Não se trata, na minha opinião, de repolitizar, senão simplesmente exigir algo básico no Direito Penal: a constatação do injusto que deve presidir toda a incriminação delitiva $[\ldots]$

Quanto à objetividade jurídica do crime em questão, isto é, o bem jurídico tutelado, pode-se dizer que se trata da ordem pública, conforme afirma MÁRIO DANIEL MONTOYA ${ }^{14}$ :

O bem jurídico tutelado é a ordem pública; é por isso que se afirma que associação ilícita afeta a tranquilidade e a paz social, não só porque a sociedade sabe de sua existência, o que provoca inquietação social,mas também ao perigo que significa para a preservação da ordem social estabelecida $[\ldots]$

Importante trazer à baila a posição de MANUEL CANCIO MELIÁ ${ }^{15}$, no sentido de que o bem jurídico tutelado nos crimes de organização criminosa seria a segurança pública, conforme segue: "[...] um ataque direto contra um bem jurídico autônomo da "paz interior" compreenderia também a "segurança pública [...]". Ainda prossegue o mesmo autor $^{16}$ no sentido de que a justificação penal para a criminalização de organizações criminosas, através da antecipação de tutela penal, se dá mediante o caráter de excepcionalidade do crime, o que justificaria a sua punição ainda que em estado de preparação.

A opção legislativa de criminalização disposta no artigo acima encontra respaldo no direito comparado, mas há de se afirmar que diversos países optaram pela não criminalização.

\footnotetext{
${ }^{14}$ Máfia e Crime Organizado, p.172.

${ }^{15}$ El injusto de los delitos de organización: peligro e significado, p.37 (tradução livre do autor).

${ }^{16}$ Ibid., 35-36 (tradução livre do autor).
} 
Corroborando o disposto acima, JOÃO PAULO BALTAZAR ${ }^{17}$ assim se manifesta a respeito do tema:

[...] na Alemanha, onde criminalidade organizada é um conceito de direito processual ou policial, que serve como critério para autorizar determinadas medidas de investigação específicas, não havendo, porém, delito de organização criminosa.

Por sua vez, o Código Penal Espanhol no art.570 ${ }^{18}$ faz menção explícita às organizações criminosas, possuindo redação muito semelhante à adotada pelo legislador pátrio.

Outro ponto que merece destaque na análise do tipo penal em questão, diz respeito à sua autonomia, vale dizer, a responsabilização criminal por outros crimes decorrentes da prática da organização criminosa ocorrerá mediante concurso material de crimes, aplicando-se a regra prevista no Código Penal Brasileiro.

Doravante o tipo penal organização criminosa tenha redação bastante precisa e que não deixa margem a dúvidas, não há que se confundir com o tipo penal do art.288 do Código Penal Brasileiro, isto é, não há conflito aparente de normas, isso porque, neste tipo penal há necessidade de 3 (três) ou mais pessoas, além, obviamente, da necessidade de ser minimamente estruturado, possuir divisão de tarefas e prática de crimes, cuja pena máxima seja superior a 4 anos, além da necessidade de estabilidade.

A respeito de tal questão, EVERTON LUIZ ZANELLA ${ }^{19}$ assim se manifestou:

Evidente que a associação não é um mero concurso eventual de pessoas, ela exige certa estabilidade de seus integrantes. Todavia, na organização, esta estabilidade é maior, visto que deve haver maior estruturação, distribuição arranjada de afazeres e, na maioria das vezes, hierarquia ou comando.

Também não há que se confundir com o art.34 da Lei 11.343/2006, no entanto, é possível responsabilizar criminalmente um indivíduo pela prática do crime de organização criminosa, nos moldes previstos na Lei 12.850/2011, cuja atuação seja voltada ao tráfico de drogas, desde que possua os elementos nela previstos, ou seja, 4 (quatro) ou mais pessoas, estruturalmente ordenada, com divisão de tarefas e prática de

\footnotetext{
${ }^{17}$ Crime Organizado e Proibição de Insuficiência, p.146.

${ }^{18}$ Disponível em:<http://perso.unifr.ch/derechopenal/assets/files/legislacion/1_20121008_02.pdf > Acesso em 08/09/2016.

19 Infiltração de Agentes e o Combate ao Crime Organizado: Análise do Mecanismo Probatório sob o Enfoque da Eficiência e do Garantismo, p.48-49.
} 
crimes com pena máxima superior a 4 anos. A associação criminosa consiste na mera associação, de 2 ou mais pessoas, sem a necessidade de divisão de tarefas ou estrutura ordenada.

Finalizando o tema a respeito da tipificação da organização criminosa, entendemos que andou bem o legislador.

A sociedade brasileira em muito vem sendo atacada pela criminalidade organizada, seja a de matiz violento ou de colarinho branco.

Fato é que ambas, a seu modo, degradam a sociedade, causam sensação de impunidade, restringem direitos, ofendem as instituições estatais, dilapidam o patrimônio público, causam pânico, desestabilizam a economia e a própria regularidade do Estado, ofendendo a paz e ordem públicas, bem jurídicos que possuem dignidade penal.

Desta forma, comungamos do entendimento de que o Estado, com base no direito à segurança como direito fundamental, conforme preleciona WINFRIED

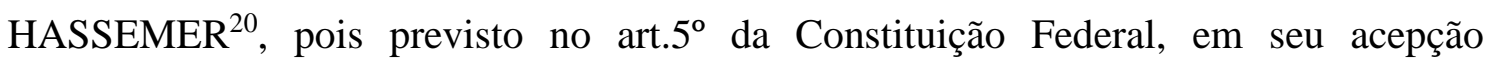
objetiva, tinha o dever de criminalizar a organização criminosa nos moldes definidos na Lei $12.850 / 2011$.

A respeito do direito à segurança, analisado como direito fundamental, algumas considerações devem ser analisadas, ainda que de maneira breve.

A doutrina constitucional, por muito tempo, limitou-se a analisar o direito à segurança previsto no art. $5^{\circ}$ da Carga Magna em uma acepção restritiva, isto é, como se relação tivesse apenas e tão somente com o direito à segurança jurídica, o eximindo de um alcance mais amplo, nomeadamente, com relação à segurança pública, pois nesse sentido, haveria previsão expressa no art.144 da Constituição Federal.

Ocorre que o direito, tal como nós, somos frutos da análise do tempo e do espaço, vale dizer, estamos sujeitos, diuturnamente, a uma releitura de nossas ações e essa interpretação hoje foi substancialmente alterada.

JOSÉ AFONSO DA SILVA ${ }^{21}$ já se manifestava de acordo com esse entendimento, qual seja, pela interpretação ampla do direito à segurança como sendo um conjunto de medidas que visa garantir todos os direitos previstos na Constituição

\footnotetext{
${ }^{20}$ Direito Penal Libertário, p.170-171.

${ }^{21}$ Curso de Direito Constitucional Positivo, p.194. 
Federal, notadamente, os previstos no art. $5^{\circ}$ da Carta Política de 1988, portanto, a segurança constitui também um direito fundamental

O próprio Supremo Tribunal Federal ${ }^{22}$ decidiu em sede do HC 87.310, da relatoria do Ministro Carlos Ayres Brito que a segurança é “[...] voltada para a preservação dos superiores bens jurídicos da ordem pública e da incolumidade das pessoas e do patrimônio [...]".

No tocante à acepção objetiva dos direitos fundamentais, também entendemos pertinente uma breve análise.

Essa interpretação é fruto da evolução do direito constitucional, especialmente, influenciado por decisões proferidas pelo Tribunal Constitucional Espanhol e Alemão, na medida em que fizeram uma releitura da acepção dos direitos fundamentais, não apenas e tão somente em sua acepção subjetiva, de direitos limitadores contra o Estado, mas também na acepção objetiva, como comandos ordenadores ao Estado, o "obrigando" a realizar o cumprimento de ordens constitucionais, principalmente, quando relacionados à proteção de direitos e garantias fundamentais.

LUCIANO FELDENS ${ }^{23}$ a respeito do tema: "Essa interpretação empresta uma nova dimensão aos direitos fundamentais, fazendo com que o Estado evolua da clássica posição de adversário para uma função de guardião desses direitos".

A doutrina alemã assim classifica a leitura dos direitos fundamentais: na acepção subjetiva, de direitos contra o Estado é denominado übermassverbot; por outro lado, na acepção objetiva, através da leitura dos direitos fundamentais, determinando ao Estado comandos proativos, no sentido de garantir e fazer valer os direitos fundamentais, denomina-se untermassverbot.

Desta forma, a tipificação de organização criminosa atende, a nosso sentir, a um dever de proteção do Estado, como imperativo de tutela, na proteção do direito à segurança como direito fundamental.

Quanto às características de uma organização criminosa, a doutrina é vasta em apontá-las e tais características são frutos da análise empírica de cada país que as apontou.

\footnotetext{
22 BRASIL, Supremo Tribunal Federal. $1^{\text {a }}$ Turma. Processual Penal. HC 87310. Ministro Carlos Ayres Brito, $1^{\text {a }}$ turma, v.u., DJU 08/08/2006.

${ }^{23}$ Direitos Fundamentais e Direito Penal, p.76-77.
} 
De todo sorte, nosso objetivo consiste em apontar algumas características que estejam presentes na maioria das organizações criminosas, sejam aquelas presentes em nosso cenário local, leia-se, Brasil, ou aquelas fruto do direito comparado.

Podemos dizer que uma organização criminosa possua características de nacionalidade ou transnacionalidade, o que significa dizer, pela primeira, o espaço territorial de atuação limita-se ao país onde soe ocorrer os crimes por ela praticados, pela segunda, teremos crimes perpetrados com alcance em outros países, além de sua origem.

A gama de exemplos de organizações criminosas de âmbito nacional é das mais amplas, a título de exemplo, a Polícia Federal foi responsável por uma investigação, cujo objetivo consistiu no desmantelamento de grupo criminoso organizado, através da Operação Sevandija ${ }^{24}$; o bojo da investigação seria a corrupção de membros do legislativo e executivo municipais da cidade de Ribeirão Preto-SP, de modo que a atuação do grupo era voltada única e exclusivamente naquela região e, portanto, em território brasileiro.

No que concerne à transnacionalidade, de igual forma, a gama de exemplos é gigantesca. A título de exemplo, a atuação das máfias, cuja violência e rigor foram maior identificadas na italiana, chinesa e japonesa, conforme ensina MÁRIO DANIEL MONTOYA ${ }^{25}:$ "[...] as mais altas estruturas das máfias, de acordo com seu rigor, são as Tríadas, a Cosa Nostra e os Yakuza."

A máfia italiana, por exemplo, entrou em processo de expansão territorial de seus negócios, a partir da imigração italiana no fim da $2^{\mathrm{a}}$ Grande Guerra Mundial para os Estados Unidos da América. Atualmente, a Cosa Nostra americana é tida como a mais famosa organização criminosa da América, segundo ANGIOLO PELLEGRINI e PAULO JOSÉ DA COSTA JR ${ }^{26}$ : "Compreende atualmente 25 famílias, com um total de 1300 agregados, que, por sua vez, dispõem de dez dependentes cada um para desempenhar atividades ilícitas, além de três mil outros, ditos soldados."

A máfia chinesa atua nos dias de hoje no contrabando de mercadorias falsas em diversos países, inclusive no Brasil.

\footnotetext{
${ }^{24}$ Disponível em: <http://www1.folha.uol.com.br/poder/2016/09/1809212-pf-deflagra-operacao-naprefeitura-de-ribeirao-preto.shtml > acesso em 12/09/2016.

${ }^{25}$ Ibid., p.3.

${ }^{26}$ Criminalidade Organizada, p.90.
} 
Não podemos deixar de mencionar as organizações terroristas, cuja disciplina vem explicitada na Lei 13.260/2016, a qual prevê, através de seu artigo $16^{27}$ a possibilidade de utilização dos mecanismos previstos na Lei 12.850/13, conforme segue, in verbis:

Art. 16. Aplicam-se as disposições da Lei n $^{\circ} 12.850$, de 2 agosto de 2013, para a investigação, processo e julgamento dos crimes previstos nesta Lei.

Organizações terroristas como Estado Islâmico, Al Qaeda entre outras, vêm atuando através de atentados em diversos países da Europa, especialmente, França e Alemanha e nos Estados Unidos da América.

Ainda no tema "características", podemos classificar uma organização criminosa como violenta e não violenta; pela primeira, seria aquela cuja atuação necessita da violência e ameaça física para consecução do seu desiderato criminoso, por exemplo, a atuação do Primeiro Comando da Capital e Comando Vermelho; pela segunda, o grupo criminoso atuaria no que conhecemos como crimes de colarinho branco, expressão cunhada por EDWIN H. SUTHERLAND ${ }^{28}$, o qual ao se manifestar a respeito da gravidade de tal estirpe de crime, externou opinião que os crimes de colarinho branco, seguramente, são mais graves que os crimes comuns, conforme segue:

Os criminosos de colarinho branco dos dias atuais são mais suaves e menos diretos que os barões do roubo do último século, mas não são menos criminosos.

$[\ldots]$

O custo financeiro do crime de colarinho é provavelmente bem superior do que o custo financeiro de todos os crimes que comumente são considerados "problemas da criminalidade". Um executivo de uma rede de supermercados em um ano desfalcou sua empresa em U\$800.000, o que representa seis vezes as perdas anais de 500 assaltos e furtos sofridos por aquela empresa.

\section{CONCLUSÃO:}

Como mencionado acima, a doutrina era vasta na identificação de diversos elementos e características que estariam aptos a identificar a existência de uma

\footnotetext{
${ }^{27}$ Disponível em: <http://www.planalto.gov.br/ccivil_03/_Ato2015-2018/2016/Lei/L13260.htm> Acesso em 12/09/2016.

${ }^{28}$ Crime e Colarinho Branco, p.35 e 37.
} 
organização criminosa, conforme aponta ANTONIO SCARANCE FERNANDES ${ }^{29}$, no entanto, estas foram apontadas antes do advento da Lei 12.850/2011, justamente, porque encontrava-se em um cenário de ausência de regulamentação legal, portanto, um hiato legislativo.

Entretanto, com a promulgação da Lei 12.850/2011, forçoso reconhecer que ela deixou pouquíssimo espaço para interpretação doutrinária e jurisprudencial, na medida em que previu os elementos que são necessários para a configuração de uma organização criminosa. Optou por um conceito relativamente aberto, de modo a poder amoldar a conduta ao tipo penal, sem muitas nuances ou elementos de difícil constatação.

Ao estabelecer como elementos objetivos do tipo os termos "estruturalmente ordenada e caracterizada pela divisão de tarefas, ainda que informalmente", o legislador ampliou o leque de atuação da lei, porém, não banalizou seu conceito, conforme ensinam CÉZAR ROBERTO BITENCOURT e PAULO CÉSAR BUSATO ${ }^{30}$ : "Organização criminosa não é uma simples reunião de pessoas que resolvem praticar alguns crimes, e tampouco a ciente e voluntária reunião de algumas pessoas para a prática de determinados crimes[...]".

\section{REFERÊNCIAS BIBLIOGRÁFICAS:}

\section{BITENCOURT, Cézar Roberto, BUSATO, Paulo César. Comentários à Lei de} Organização Criminosa. São Paulo: Editora Saraiva, 2016.

FELDENS, Luciano. Direitos Fundamentais e Direito Penal. Porto Alegre: Editora Livraria do Advogado, 2008.

FERNANDES, Antonio Scarance. O Equilíbrio na Repressão ao Crime Organizado. In: Crime Organizado, Aspectos Processuais, Coordenação Antônio Scarance Fernandes, José Raul Gavião de Almeida e Maurício Zanoide de Moraes. São Paulo: Editora Revista dos Tribunais, 2009.

\footnotetext{
${ }^{29}$ Em obra sobre o tema, aponta como características: "[...] associação permanente e estável de diversas pessoas; estrutura empresarial, hierarquizada e piramidal, com podre concentrado nas mãos dos líderes, os quais não mantêm contato diretamente com as bases; poder elevado de corrupção; uso de violência e de intimidação para submeter os membros da organização e para obter a colaboração ou o silêncio de pessoas não participantes do núcleo criminoso; finalidade de lucro; uso de sistemas de lavagem de dinheiro para legalizar as vultosas somas obtidas com as práticas delituosas; regionalização ou internacionalização da organização; o uso de modernas tecnologias. Crime Organizado, Aspectos Processuais, p.13.

${ }^{30}$ Comentários à Lei de Organização Criminosa, p.26.
} 
GODOY, Luiz Roberto Ungaretti. Crime Organizado e seu Tratamento Jurídico Penal. São Paulo: Editora Elsevier, 2010.

GOMES, Rodrigo Carneiro. O crime organizado na visão da Convenção de Palermo. $2^{\text {a }}$ Edição, Belo Horizonte: Editora Del Rey, 2009.

GÜNTHER, Jakobs, POLAINO-ORTS, Miguel. Delitos de organización: un desafío Al Estado. Primera edición, Perú: Editora y Librería Jurídica Grijley.

HASSEMER, Winfried. Direito Penal Libertário, Del Rey Internacional 6, apresentação Gilmar Ferreira Mendes. Tradução Regina Greve. Belo Horizonte: Editora Del Rey, Belo Horizonte, 2007.

JÚNIOR, João Paulo Baltazar. Crime Organizado e Proibição de Insuficiência. Porto Alegre: Editora Livraria do Advogado, 2010.

MONTOYA, Mário Daniel. Máfia e Crime Organizado. Rio de Janeiro: Editora Lumen Juris, 2007.

MELIÁ, Manuel Cancio. El injusto de los delitos de organización: peligro e significado. Disponível em <https://www.unifr.ch/ddp1/derechopenal/articulos/a_20080521_44.pdf>

PINTOMBO, Antônio Sérgio Altieri de Moraes. Organização Criminosa, Nova Perspectiva do tipo legal. $1^{\text {a }}$ Edição, São Paulo: Editora Revista dos Tribunais, 2009.

SILVA, José Afonso. Curso de Direito Constitucional Positivo. $30^{\text {a }}$ Edição, São Paulo: Editora Malheiros, 2008.

SUTHERLAND, Edwin H. Crimes de Colarinho Branco versão sem cortes. $1^{a}$ Edição, Rio de Janeiro: Editora Revan, 2015.

ZANELLA, Everton Luiz. Infiltração de Agentes e o Combate ao Crime Organizado, Análise do Mecanismo Probatório Sob o Enfoque da Eficiência e do Garantismo. $1^{\text {a }}$ Edição, Curitiba: Editora Juruá, 2016. 